NO.10 Journal of Petroleum Research \& Studies ( JPR \& S)

\title{
Synthesis of Local Demulsifiers and Evaluation in Iraqi Oil Fields
}

Zaidoun Kh. Kuraimid; Azhar A. Sharef; Buthaynaa Khalil Ibraheem

$$
\text { P.R.D.C }
$$

\section{$\underline{\text { Abstract }}$}

De-emulsifiers are one of the important industrial additives used commonly in petroleum industry in order to separate the salt water from crude oil in wet crude oil fields of south oil company (S.O.C) in Iraqi fields.

In the present study, it has been prepared local demulsifies by synthesis Gemini surfactants bis (Quaternary ammonium salt). The local de-emulsifier was assessed in the laboratories of South Oil Company (S.O.C) Comparison with the results of commercial de-emulsifier (A), where the local material efficiency was higher than the important commercial (A) adopted in the S.O.C by bottle Test and later was produced (6) barrels of material prepared and evaluated in AL-SHAMIA Degassing station in Iraqi South Rumaila .

Where, evaluated the local de-emulsifier in the fields and show the positive results, this describes the evaluation of field emulsifying the local material in this study with lost cost of preparation of a one barrel about $500 \$$ in the time that the cost of one barrel of commercial de-emulsifier is $1000 \$$.

The assessment was in the conditions of commercial de-emulsifier, depending on the natural of Dehydrator and Desolater in addition of the effective Dose is $25 \mathrm{ppm}$ and by $100 \%$ separation efficiency in same fresh oil source.

The efficiency of local de-emulsifier studied varity of parameters like: Temperature and the time required to separation function of the Dose. 


\section{NO.10 Journal of Petroleum Research \& Studies ( JPR \& S)}

The field evaluation conditions of local de-emulsifier were under control outside of the oils (fresh) of $\mathrm{D}_{2}$ (Desolater) of isolation units to examine all of the water and salt content of crude oil.

\section{Introduction}

Production of crude oil from the depth of earth to be a companion amount of water and salt to be called (W/O Emulsion) formula So that the two miscible phases water and oil can't be separated in isolated units on site by teams of density depending on the depth of crude oil contain heavy asphaltenes which is considered a contributing factor in the adhesion of oil globules of water through the film. [1]

The presence of water in emulsions (in crudes) present several problems during processing as well as during recovery such as the increased viscosity and hence increased pumping costs, pipeline corrosion, hampering of Skimmer operation, increased handling of oily waste disposal and storage problems ...etc. These emulsion may contain water cut is about (20-40\%) in Iraqi oil reservoir and frequently extremely stable due to the presence in the emulsion of a variety of emulsifiers such as asphaltemes.

Iraqi south oil company S.O.C consumption of the commercial de-emulsifiers is between (1200-1500) barrel/month.

De-emulsifiers is a chemical monopoly companies production of specific works of this material on the configuration of a system with stabilizing high through the formation of two phases separate, depending on the chemical structure of this material containing aggregates hydrophilic group and other lipophilic there by realizing the separation process and efficiency depending on the natural of the material used the additives and many of the factors in the production processes in the plant electrical insulation of precipitators operating, according to the mechanics de-emulsifier adsorption at the critical meeting point of the material by emulsion, which is accompanied by a decrease in free energy $\Delta \mathrm{G}$ and entropy $\Delta \mathrm{S}$. [5]. 


\section{NO.10 Journal of Petroleum Research \& Studies ( JPR \& S)}

There is also a factor increasing the aggregation and composition of the emulsion droplets are cluster for a short time and thus destroy of the emulsion structure and separation of phases.

The type of insulators pressure allocated to crude oil processing plants in the insulation field with high pressure (NGKo type) 500 psi and other low pressure (Excci type) and commencing to 105 psi.

In this, research the preparation of local material of de-emulsifier through organic synthesis of a new type of Gemini surfactants [bis (Quaternary ammonium)] with the type of poly oxy ethylene derivatives help to break the adhesion and the selection of two types of solvents.

In this study were prepared Gemini surfactants and selection because of its ability to double in reducing the surface tension due to have two lipophilic chain and two hydrophilic groups from of activated two molecules (Dimeric surfactants) make it the ability to reduce the critical micellization concentration (C.M.C) and the formation of two phases may not be miscible, as is the case in the compounds prepared in the search. [3]

The field evaluation depending on the dose used the measured equation (1)

Dose $=\frac{\text { Spent } \frac{l}{h} \times 1000 \frac{m i l}{l}}{\text { Production Capacity } \frac{m^{3}}{h}} \ldots$

Where, the production capacity of AL SHAMIA station was 45000 barrels/day.

The specification of crude oil outside after the treatment by use the prepared local de-emulsifier [5]

- Water content $=$ trace.

- Salt content $=8.2 \mathrm{ptb}\{\mathrm{ptb}($ pond $/ 1000$ barrel $)\}$.

While the specification of crude oil outside after treatment by used of commercial de-emulsifier is: 


\section{NO.10 Journal of Petroleum Research \& Studies ( JPR \& S)}

- Water content $=$ trace.

- Salt content $=11.9$ ptb.

\section{Experimental Work}

\section{Material \& methods}

Material: fresh crude oil from North Rumaila field and South Rumaila field (Quarinat \&Shamia) station for field evaluation.

Material evaluation: laboratory-prepared materials of local de-emulsifier leading to production (6) barrel of this material.

\section{Preparation and Evolution of Local De-emulsifier}

Bis-quaternary ammonium salt (1, 2-bis (cetyl tetra methyl ethylene ammonium bromide) was prepared in two naked round bottomed flask fitted with separating funnel and condenser. A solution of (1) mole of TMEDA(N,N,N,N-Tetramethyl ethylene diamine ) and 2 mole of cetyl bromide was added drop wise by the separating funnel for $60 \mathrm{~min}$ at $50^{\circ} \mathrm{C}$. After the addition, it was completed.

The temperature rise to $80^{\circ} \mathrm{C}$ and the reaction was continues for 24 hours. The solvent then evaporated by rotary evaporator. The product was a white solid material, which was dried and the re-crystallized with a mixture of hexane and ethanol (1:1).

The product was soluble in water, xylene and toluene. The yield was $67.5 \%$, with chemical structure $\mathrm{C}_{38} \mathrm{H}_{82} \mathrm{~N}_{2} \mathrm{Br}_{2}$.

The prepared bis (Quaternary ammonium) add to one of poly oxy ethylene derivatives and prepare new formula by added suitable solvent and other additives to produce $\left(\mathrm{Z}_{1} \& \mathrm{Z}_{2}\right)$ according to the modification of ratio of ingredients. [5]. 
NO.10 Journal of Petroleum Research \& Studies ( JPR \& S)

\section{Evaluation Stages}

Laboratory stage using the bottle test and dose in (ppm) while taking a function of temperature and time compared with the important commercial de-emulsifier A $\&$ B. As in the tables (1-4) and figures (1-4):

Table (1)

\begin{tabular}{|c|c|c|c|}
\hline \multicolumn{4}{|c|}{$\begin{array}{l}\text { Crude oil: South Rumaila/ Main pay } \\
\text { Oil/Water Percent (vol.): [oil 84\% + Water 16\%] } \\
\text { Dose: } 100 \text { PPM }\end{array}$} \\
\hline \multirow{2}{*}{ Time (Min.) } & \multicolumn{3}{|c|}{$\%$ Water Separation } \\
\hline & $\mathrm{Z}_{1}$ & $\mathbf{Z}_{2}$ & $\mathbf{A}$ \\
\hline 10 & 0 & 40.6 & 12.5 \\
\hline 30 & 0 & 56.3 & 53.1 \\
\hline 60 & 0 & 70.3 & 68.8 \\
\hline 90 & 25 & 93.8 & 87.5 \\
\hline 120 & 43.8 & 100 & 90.6 \\
\hline
\end{tabular}

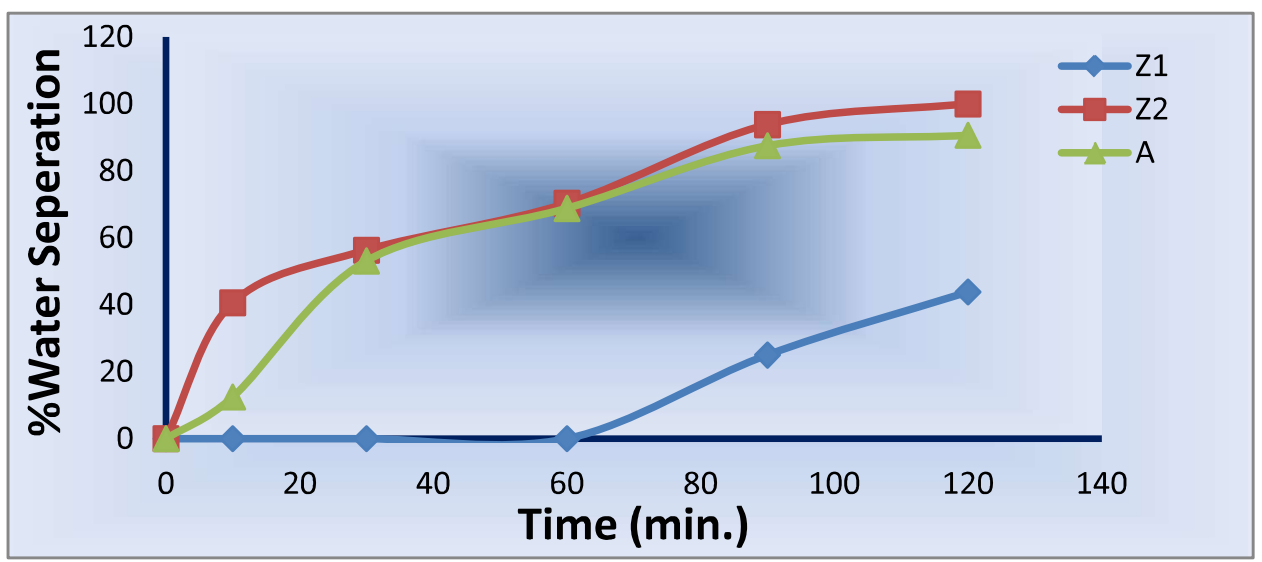

Fig. (1) the separation efficiency of de-emulsifiers Z1\&Z2 compare with commercial deemulsifier (A) with time at $50^{\circ} \mathrm{C}$ on south Rumaila Crude oil emulsion treatment in S.O.C Lab 
Table (2)

\section{Crude oil: North Rumaila}

Oil/Water Percent (vol.): 15\% [oil 85ml + Water 15ml]

Total volume: $100 \mathrm{cc}$

Dose: 60 PPM , Temperature $=65^{\circ} \mathrm{C}$, Mixing Time $=30$ Min $/ 1300$ RPM

\begin{tabular}{|c|c|c|c|c|}
\hline \multirow{2}{*}{ Time (Min.) } & \multicolumn{5}{|c|}{ \% Water Separation } \\
\cline { 2 - 5 } & $\mathbf{Z}_{\mathbf{1}}$ & $\mathbf{Z}_{\mathbf{2}}$ & $\mathbf{B}$ & $\mathbf{A}$ \\
\hline $\mathbf{3 0}$ & 15 & 15 & 13 & 13 \\
\hline $\mathbf{6 0}$ & 15 & 15 & 13 & 13 \\
\hline $\mathbf{1 2 0}$ & 15 & 15 & 13 & 13 \\
\hline $\mathbf{2 4 0}$ & 15 & 15 & 13 & 13 \\
\hline
\end{tabular}

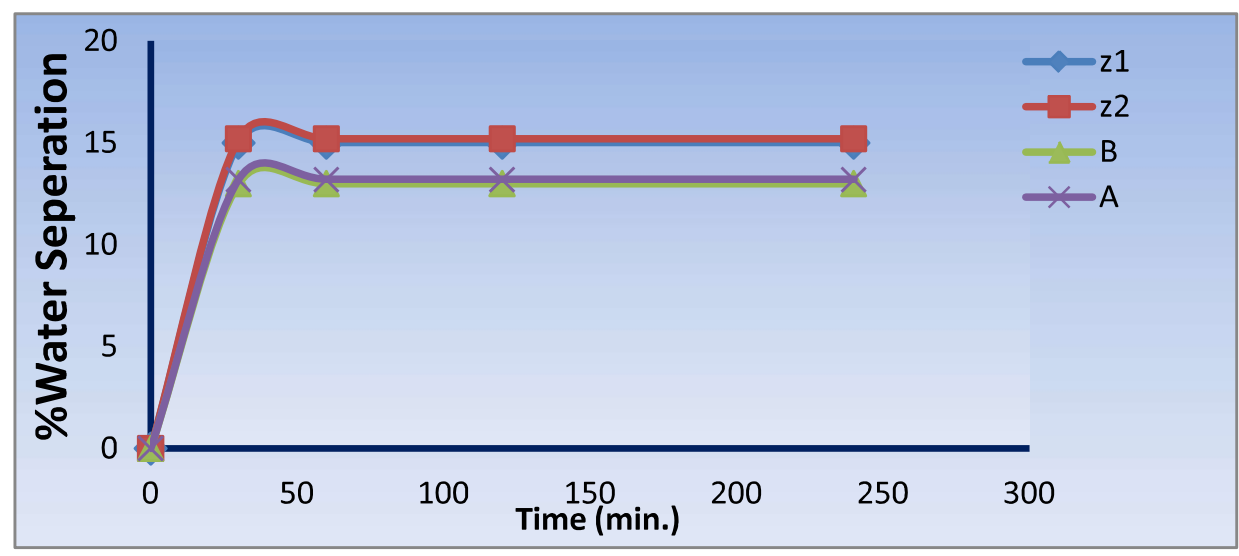

Fig. (2) The separation efficiency of prepared de-emulsifiers Z1\&Z2 compare with commercial A and B with time at $50^{\circ} \mathrm{C}$ on north Rumaila emulsion in PRDC Lab

\section{Table (3)}

\begin{tabular}{|c|c|c|c|}
\hline \multicolumn{4}{|c|}{$\begin{array}{c}\text { Crude oil: North Rumaila/ Zubair } \\
\text { Dose: 100 PPM }\end{array}$} \\
\hline \multirow{3}{*}{ Time (Min.) } & \multicolumn{3}{|c|}{ \% Water Separation } \\
\cline { 2 - 4 } & $\mathbf{Z}_{\mathbf{1}}$ & $\mathbf{Z}_{\mathbf{2}}$ & $\mathbf{A}$ \\
\hline $\mathbf{1 0}$ & 34 & 18.8 & 25 \\
\hline $\mathbf{3 0}$ & 50 & 50 & 56.3 \\
\hline $\mathbf{6 0}$ & 62.5 & 96.6 & 87.5 \\
\hline $\mathbf{9 0}$ & 96.9 & 96.9 & 93.8 \\
\hline $\mathbf{1 2 0}$ & 96.0 & 96.9 & 96.9 \\
\hline
\end{tabular}


NO.10 Journal of Petroleum Research \& Studies ( JPR \& S)

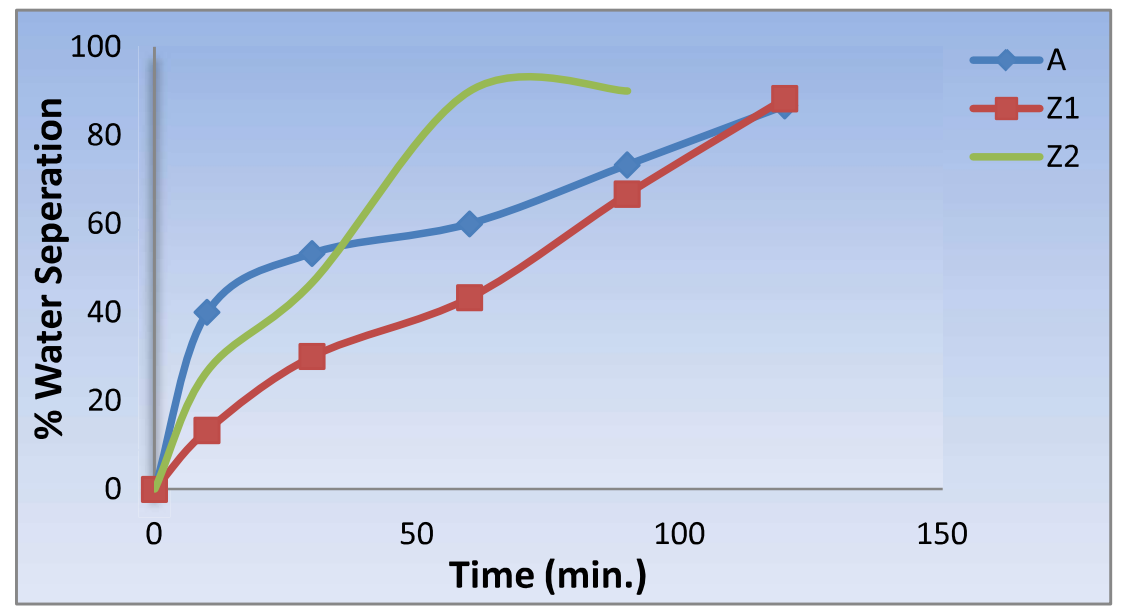

Fig. (3) The separation efficiency of prepared de-emulsifiers Z1\&Z2 compare with commercial A with time at $50^{\circ} \mathrm{C}$ on north Rumaila Crude oil emulsion/ Zubair location in S.O.C Lab

Table (4)

\begin{tabular}{|c|c|c|c|}
\hline \multicolumn{3}{|c|}{$\begin{array}{c}\text { Crude oil: North Rumaila/ Mishrif } \\
\text { Dose: } 100 \text { PPM }\end{array}$} \\
\hline \multirow{3}{*}{ Time (Min.) } & \multicolumn{3}{|c|}{ \% Water Separation } \\
\cline { 2 - 4 } & $\mathbf{Z}_{\mathbf{1}}$ & $\mathbf{Z}_{\mathbf{2}}$ & $\mathbf{A}$ \\
\hline $\mathbf{1 0}$ & 13.3 & 26.7 & 40 \\
\hline $\mathbf{3 0}$ & 30 & 46.7 & 53.3 \\
\hline $\mathbf{6 0}$ & 43.3 & 90 & 60 \\
\hline $\mathbf{9 0}$ & 66.7 & 90 & 73.3 \\
\hline $\mathbf{1 2 0}$ & 88.3 & 91.7 & 86.7 \\
\hline
\end{tabular}

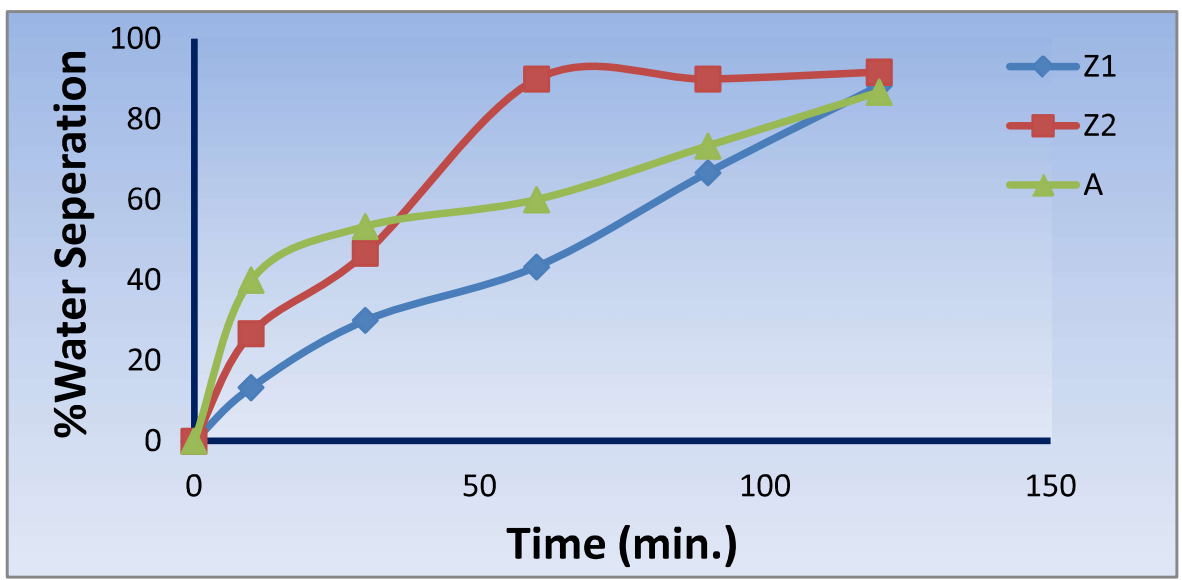

Fig. (4) The separation efficiency of prepared de-emulsifiers Z1\&Z2 compare with commercial A with time at $50^{\circ} \mathrm{C}$ on north Rumaila Crude oil emulsion/ Mishrif location in S.O.C 


\section{NO.10 Journal of Petroleum Research \& Studies ( JPR \& S)}

\section{Result and Discussion}

The test results indicators high positive depending on the type of oil and the concentration of the dose, which is directly ejective to the efficiency and the time of separation in addition to study the effect of additives used with prepared local de-emulsifier depending on the integration of structure breakers emulsification of the preservatives and materials increase the stabilizing material and to ensure breaking the film between phases, taking into consideration the factors used in the field and specifically in the site evaluation in the AL SHAMIA station of the south Rumaila Iraqi southern oil company.

According power transformer with a polarity within the buffer in the form of electrostatic field and therefore easy flow phases separated, as well as the degree of reservoir (Main pay, Mishrif, Zubair) where is not used the heating in the AL SHAMIA station), and only evaluation depending on the temperature of the reservoir oil between $\left(45-60^{\circ} \mathrm{C}\right)$, and thus influence the surface tension of the liquid depending on the relationship (R. vonetoves), which represents the relationship between molare surface and temperature in equation No.(2) [4].

$$
\gamma(M v)^{\frac{2}{3}}=\mathrm{a}-\mathrm{Kt}
$$

The selection of Gemini surfactant was according on HLB value scale.

Though the practical results of field proven the prepared in this research Z1 \& Z2 are clearly superior in the efficiency of separation and low cost of production per barrel economic compared with commercial de-emulsifier and back over the new chemical formula has proven operating wells containing rations of water cut (20$40) \%$ in operating wells in the evaluation period: $\mathrm{Ru}$ (22- 24- 53- 61- 82- 101107- 109- 112- 124).

The date of inspection field and testing in the ALSHAMIA station 23/August/2011 on the (Blank B) and the rate of salt emerging after treatment 
NO.10 Journal of Petroleum Research \& Studies ( JPR \& S)

using prepared de-emulsifier is (8.2 ptb) and dose ( $25 \mathrm{ppm})$ with stabilizing the full contingent of isolation during the period of evaluation and testing field (and the absence of amperage sudden), which indicates the stabilizing material and separation efficiency of the process and table below the shows the staged of examination, temperature, the conditions and the rate of wash water which used in the station.

\section{Conclusions}

The study of performances of two local demulsifier and applied in south oil company station which consider a rigid emulsion of crude oil, where from bottle test and field evolution revealed the following:

- The performances of de-emulsifiers increase with increase concentration of deemulsifier at temperature constant.

- The performances of de-emulsifiers depending on the temperature in field evaluation (morning \& night).

- S.O.C can use this material Z1 \& Z2 a production line or an additional alternative in the consumption of commercial de-emulsifier. 


\section{Journal of Petroleum Research \& Studies}

\section{References}

1. K. K. Salam, A. O. Alade, A. O. Arinkoola, A. Opawale; "Improving the Demulsification Process of Heavy Crude Oil Emulsion through Blending with Diluent Petroleum Engineering Unit, Department of Chemical Engineering, Ladoke Akintola University of Technology (LAUTECH), PMB 4000, Ogbomoso, Nigeria, (2013).

2. F. M. Menger and J.S. Keiper; "Synthesis of Gemini surfactants (dimeric) and related surfactants", Angew - Chem. Int" 39, 1906 - 1920, (2000).

3. R. Oda, I. Huc, D.Danino, Y. Talmon,; "Effect of the hydrophilic size onthe structural phases of aqueous nonionic gemini surfactant solutions" J.Am. Chem. Scc, 16, 9759 - 9769, (2000).

4. T. Leslie; "synthesis of Gemini and trimeric surfactants" Emory Univ., Ph. D. Thesis USA., (1994).

5. Z. KH. Kurimid; "Synthesis and Evaluation of New Gemini De-emulsifiers", M.Sc. Thesis, Basra Univ., Iraq, (2004). 